ISSN: 0213-2079 - ISSN electrónico: 2386-3889

DOI: https://doi.org/10.14201/shhmo2021431229257

\title{
LOS ARCHIVOS DEL CARDENAL. EL FONDO DOCUMENTAL SEVILLANO DE D. JUAN PARDO TAVERA
}

\section{The archives of the Cardinal: Juan Pardo Tavera and his Sevillian documentary collection}

\author{
Antonio SÁNCHEZ GONZÁLEZ \\ Universidad de Huelva \\ antonio.sanchez@dhis2.uhu.es \\ ORCID: https://orcid.org/0000-0001-5025-455X
}

Fecha de recepción: 21/04/2020

Fecha de aceptación: 15/03/2021

RESUMEN: La figura del cardenal Juan Pardo Tavera (1472-1545), «mano derecha» del emperador Carlos V, generó numerosa documentación hoy conservada en los grandes Archivos españoles. Pero, por sí mismo, el cardenal originó tres Archivos patrimoniales: el de sus bienes iniciales en el reino de Sevilla, que nos ocupa, el familiar de los marqueses de Malagón y el del Hospital de San Juan Bautista que fundó en Toledo.

En el reino de Sevilla, Juan Tavera adquirió un patrimonio importante durante la primera etapa de su carrera eclesiástica, integrado principalmente por bienes rústicos, cuyo fondo documental damos aquí a conocer en cuanto a su contenido, así como su sistema de organización y descripción archivístico. Esta documentación recaló más tarde en el Archivo Ducal de Medinaceli, donde hoy conforma la sección «Partido de Sevilla».

Palabras clave: Cardenal Tavera; Fray Diego de Deza; reino de Sevilla; documentación patrimonial; casas y cortijos. 
ABSTRACT: The figure of Cardinal Juan Pardo Tavera (1472-1545), main counsellor of the Emperor Carlos V, is related to a large documentary fund which is currently distributed among the great Spanish Archives. The Cardinal himself created three patrimonial archives: one involving his initial estates in the kingdom of Seville, which is our concern in this work, the family archive for the Marquises of Malagón and a third one for the Hospital of Saint John the Baptist, which he founded in Toledo.

Juan Tavera acquired an important patrimony during the first stage of his ecclesiastical career in the kingdom of Seville, consisting mainly of land property. In this work, we will describe the archives for this initial period and will also study their organization and contents. This documentary fund ended up in the Ducal Archive of Medinaceli, where it is currently labelled as section «Partido de Sevilla».

Keywords: Cardinal Tavera; friar Diego de Deza; kingdom of Seville; patrimonial documentation; houses and country estates.

\section{INTRODUCCIÓN}

Los Archivos surgen y se forman con la documentación generada por las instituciones, así como por las personas que han ejercido una mayor influencia en la sociedad de su tiempo y que se granjearon un patrimonio. Fue el caso del prelado castellano Juan Pardo Tavera (1472-1545) que, de capellán de iglesia local, llegó a ocupar la sede cardenalicia primada de España, además de convertirse en la «mano derecha» de Carlos V y en uno de los artífices de la grandeza del Imperio español.

Bajo cobijo inicial de su tío fray Diego de Deza (1443-1523), principalmente durante la larga final etapa del dominico como arzobispo hispalense, Juan Pardo se labró una carrera eclesiástica que le llevó a ascender altas cotas hasta el punto, como decimos, de alcanzar el arzobispado de Toledo. Pero Tavera no solo prestó innumerables servicios a la Iglesia sino también a la Monarquía como uno de los apoyos imprescindibles del emperador, llegando a ostentar temporalmente el gobierno de España como regente del Reino, en ausencia de Carlos $V$ y por enfermedad de la reina.

Tanto en su labor pastoral al frente de diversas diócesis como en el servicio a la Monarquía, su memoria ha quedado depositada en los grandes Archivos eclesiásticos y generales de este país. Pero nosotros no nos fijamos aquí en ellos, sino en aquellos otros fondos documentales que el prelado originó a nivel personal como consecuencia de su patrimonio particular, que se transmitieron por vía familiar. Pues, como consecuencia de los grandes servicios prestados y de los relevantes cargos

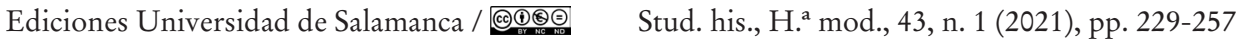


que ejerció, acumuló una hacienda nada desdeñable, localizada principalmente en el reino de Sevilla y, en menor medida, también en Toledo.

Con tales estipendios - más por los que recibió en contraprestación a sus servicios al trono que por los del altar-, benefició considerablemente a la descendencia de su único hermano, en particular al hijo varón, el mariscal de Castilla Arias Pardo de Saavedra, quien recibiría sucesivamente del cardenal hasta tres importantes donaciones por vía de mayorazgo, entre 1517 y 1532, aparte de otros bienes legados con posterioridad e igualmente vinculados por línea regular de primogenitura, sin dejar de atender, por ello, las dotes y otras necesidades de sus sobrinas, las hermanas de dicho Arias Pardo, y sobre todo el hospital que fundó en Toledo, al que dejó por su heredero ${ }^{1}$.

En Sevilla, además de las casas principales de la calle de Abades, junto a la catedral, poseyó un conjunto importante de propiedades rústicas en lugares próximos como Utrera, Constantina, Villanueva del Río, Valencina del Alcor, Las Cabezas de San Juan y otros localizados principalmente en el Aljarafe sevillano, así como pingües rentas en la propia ciudad hispalense y su entorno.

Nos ocupamos aquí de este fondo patrimonial del prelado referido al reino de Sevilla, dejando aparte el estudio de otros fondos de los bienes de D. Juan Tavera que generaron depósitos particulares como el ya realizado de su familia - los Malagón ${ }^{2}$ - (Sánchez, 2021a y 2021b, ambos trabajos en prensa) y el de su hospital toledano ${ }^{3}$, que queda para otra ocasión, todos ellos curiosamente gestionados hoy por la Fundación Casa Ducal de Medinaceli ${ }^{4}$.

1. Por encima de todo, Juan Pardo Tavera benefició a sus criados y, aún más, a la gente más humilde y necesitada de la sociedad, en tanto que por vía testamentaria nombró heredero universal de sus bienes al Hospital que fundó y sostuvo extramuros de Toledo, bajo la advocación de San Juan Bautista, conocido como de Afuera, situado frente a la puerta de la Bisagra. Este hospital toledano prestó servicios sanitarios hasta muy avanzado el siglo XX.

2. La Casa de los marqueses de Malagón tuvo Archivo propio, que se agregó al de los duques de Santisteban del Puerto en el siglo XVIII y, con este en 1818, al de los duques de Medinaceli.

3. El Archivo del Hospital San Juan Bautista aún permanece emplazado en un ala del propio edificio fundado, a tal efecto, por el cardenal en Toledo. En otra ala del mismo inmueble se ubica, desde 1993, el Archivo de la Nobleza española, antigua sección del Archivo Histórico Nacional.

4. El Archivo del Hospital, aun cuando pertenece a la Fundación San Juan Bautista, ésta se encuentra administrada actualmente por la Fundación Medinaceli. Como heredero universal del cardenal Tavera, en el hospital toledano de San Juan Bautista debió permanecer también depositada la documentación del prelado que fue inventariada entre los bienes que quedaron tras su muerte. En dicho inventario, realizado en Valladolid en 1545, se hace mención - junto con dos cofres «de Flandes encorado [...] en que estaban escrituras de Su Majestad» - a «un arca encorada [..] dentro de la qual estauan y declararon estar escrituras del cardenal» (Melgosa, 2017: 28 , nota 34).

Ediciones Universidad de Salamanca / అ@@ Stud. his., H. ${ }^{a}$ mod., 43, n. 1 (2021), pp. 229-257 


\section{JUAN PARDO TAVERA (1472-1545), UNA VIDA DEDICADA AL ALTAR Y AL TRONO}

Por sus biógrafos (principalmente Salazar, 1603), sabemos que Juan Pardo Tavera había nacido en Toro el 16 de mayo de 1472, en el seno de una familia de la nobleza castellanoleonesa, segundogénito del matrimonio formado por Arias Pardo y Guiomar Tavera 5 .

Huérfano de padre a corta edad, fue criado por su madre, junto con su único hermano Diego, en la villa de Madrigal. En Salamanca recibió enseñanzas de latinidad y retórica por parte de su preceptor, el maestro Gumiel. Inmediatamente se graduó como bachiller de Cánones en la Universidad salmantina, en lo que sería el comienzo de una carrera eclesiástica fraguada al amparo de su tío materno, el dominico fray Diego de Deza ${ }^{6}$, que por aquellos años era precisamente obispo de Salamanca (Cotarelo, 1902 y Gámez, 2014). Este parentesco supuso la inserción progresiva de Juan Pardo en el grupo político fernandino de la Corte, formado en torno al Rey Católico.

Su primer beneficio eclesiástico fue una capellanía en la parroquia de San Adrián de Salamanca, e inmediatamente fue nombrado racionero de la catedral de Zamora por parte por parte del propio obispo Deza. En 1500 obtuvo el bachillerato en Decretos, para alcanzar posteriormente los grados de licenciado y de doctor, llegando a ser Rector de la Universidad salmantina - elegido por unanimidad - entre 1504 y 1506. En este último año Juan Pardo ocupó una plaza de oidor en el Consejo de la Inquisición.

Poco después fray Diego de Deza, siendo ya arzobispo de Sevilla, nombró a su sobrino canónigo de la catedral hispalense y, al año siguiente, lo elevó a la dignidad de chantre'; además fue provisor, oficial y vicario general del arzobispado, donde ya dio buena cuenta de sus cualidades de gobierno, compostura y honestidad. Sirviendo en este cargo, el arzobispo sevillano requirió a su sobrino que despachara directamente en la Corte algunos asuntos importantes de la archidiócesis hispalense, como el de negociar aspectos referentes a la consecución y dotación, económica y de cátedras, del Estudio General sevillano (Melgosa, 2017: 14). Estos despachos le permitieron

5. También hemos manejado las obras de Cardona, 1951; Gan Giménez, 1988: 91-126 y Martínez Millán (ed.), 2000, III: 316-325, así como la biografía de la RAH elaborada por Ezquerra Revilla.

6. El dominico era primo hermano de Guiomar Tavera, la madre de Juan Pardo Tavera, como hijo de Inés Tavera y de Antonio de Deza. Los abuelos comunes de ambos fueron Juan Rodríguez Tavera «el Viejo» vecino y regidor de Toro, y Marina de Deza.

7. Real Academia de la Historia (RAH), Colección Salazar y Castro (Col SyC), A-13, fol. 34 (n. 1473 de inventario): Carta del arzobispo a Fernando el Católico en recomendación de su sobrino el chantre hispalense (Sevilla, 13 agosto 1509).

Ediciones Universidad de Salamanca / @@ Stud. his., H. ${ }^{a}$ mod., 43, n. 1 (2021), pp. 229-257 
acudir a algunas audiencias con el rey Fernando, pudiendo comprobar el monarca las altas dotes del vicario sevillano. Por esta razón, el soberano le confió en 1513 la visita y reforma de la Real Chancillería de Valladolid, realizando Tavera una labor legisladora magistral. Como recompensa recibió al año siguiente la silla episcopal de la diócesis de Ciudad Rodrigo.

También confió en el obispo Tavera el cardenal Cisneros, a quien el regente le comunicaba los principales asuntos del Estado y le pedía su parecer. Probablemente su claro posicionamiento fernandino le hizo temer consecuencias negativas con la llegada de Carlos V a Castilla, pero pronto quedó también claro el solapamiento de intereses entre este grupo - del que Tavera formaba parte - y los servidores flamencos del nuevo monarca. De hecho, de inmediato el cardenal Adriano de Utrecht, consejero del emperador, a fines de 1521 le envía como embajador a Lisboa para concertar el doble matrimonio entre el propio emperador con la princesa Isabel de Portugal, hermana del nuevo rey luso Juan III, y el de este con la infanta Catalina, hermana a su vez de Carlos V (Salazar, 1603: 68-69). Dichos enlaces matrimoniales se celebrarían en los años inmediatos.

En 1522, al subir al solio pontificio el cardenal Adriano de Utrecht como Adriano VI, el papa invitó a Juan Pardo Tavera a que le siguiera a Roma para ocupar un alto cargo en la Santa Sede, pero el obispo de Ciudad Rodrigo rechazó este atractivo ofrecimiento excusándose en el gran respeto que le debía al emperador, seguro de que también le necesitaba. Tanto era así que, en septiembre de ese mismo año, Carlos V le nombraba presidente de la Real Chancillería de Valladolid, estableciéndose desde entonces una colaboración tan estrecha entre ambos que no cesaron en el obispo Tavera los nombramientos y la ocupación de cargos eclesiásticos y políticos a instancias del propio emperador. Sopesado su paso a la sede episcopal de León, fue designado obispo de Osma a fines de 1523 y arzobispo de Santiago de Compostela en junio de $1524^{8}$. Ese mismo año fue elegido presidente del Consejo Real (o Consejo de Castilla), cargo que ejerció durante tres lustros ${ }^{9}$, y obtuvo el cardenalato con título de San Juan ante Portam Latinam en febrero de $1531^{10}$, y el arzobispado primado de Toledo en abril de $1534^{11}$.

Su cargo de presidente del Consejo de Castilla le obligó a vivir en la Corte, alejado de sus obligaciones diocesanas, cosa que el prelado echó siempre en falta. Por

8. Sobre esta etapa compostelana ha tratado Olivera, 1999. Véase, además, RAH, Col SyC, n. ${ }^{\text {os }} 33445,33446,33513$ y 42694 del inventario de Cuartero y Vargas.

9. Sobre intervenciones suyas como presidente del Consejo véase RAH, Ibidem., n. ${ }^{\text {os }}$ $6297,33425,33440,33460,33464,33465,33466,33468,33469,33473,33474,33482$, 33485, $33486,33487,33496,33501,33503$ y 33504 .

10. Véase RAH, Col SyC, A-45 fol. 441 n. 7228 y 33426.

11. Sobre esta etapa de Tavera al frente de la sede primada de Toledo, véase RAH, Ibidem., n. ${ }^{\text {ss }}$ de inventario, por orden cronológico, 33427, 33481, 7238, 33480, 36461 y 69755.

Ediciones Universidad de Salamanca / @®@@ Stud. his., H. ${ }^{a}$ mod., 43, n. 1 (2021), pp. 229-257 
este motivo Tavera hubo de asistir a las cortes celebradas en Toledo en 1525 , a las de Madrid en 1528, Segovia en 1532, otras de Madrid en 1534, además de presidir las cortes de Valladolid en 1537 y las de Toledo del año siguiente. Una excepción, en lo que se refiere a su dedicación propiamente eclesiástica, fue haber podido organizar en 1536 el sínodo o concilio provincial de Toledo (Martínez-Burgos, 1997: 285-302).

Durante todo ese tiempo el cardenal primado había actuado también como consejero de la emperatriz en las regencias que ella desempeñó con ocasión de los continuos viajes del emperador por Europa y, consecuentemente, de sus dilatadas ausencias de España. A veces por enfermedad de $\mathrm{D}^{\mathrm{a}}$. Isabel de Portugal, como en 1529, había tenido que actuar Tavera como gobernador de los reinos españoles, e incluso a la muerte de la emperatriz, acaecida diez años después, fue nombrado gobernador efectivo o regente del Reino durante dos años cuando el emperador se trasladó a sofocar la rebelión de Gante en 1539 (Rumeu, 2006: 166).

El cardenal consigue entonces que, por fin, Carlos V le permita abandonar la presidencia del Consejo de Castilla pero, a cambio, además de gobernador le nombra Inquisidor General. En cualquier caso, pudo Tavera entonces dedicarse más ampliamente a su diócesis, que visitó en 1542 y 1543. Por esas fechas, el 15 de noviembre de ese último año, el arzobispo de Toledo ofició en Salamanca la ceremonia matrimonial del príncipe Felipe con la infanta María Manuela de Portugal. Meses después, oficiaría en Valladolid las exequias de esta princesa, fallecida el 12 de julio de 1545 sin llegar a ser reina de España, cuatro días después del parto del infante Carlos. Y allí mismo Juan Pardo Tavera enfermó gravemente, falleciendo en la madrugada del 1 de agosto inmediato, tras testar los dos días anteriores a su muerte dejando como heredero de sus bienes al hospital de San Juan Bautista que había fundado en Toledo ${ }^{12}$.

La pérdida del cardenal fue muy lamentada por el emperador, quien siempre le consideró la mejor cabeza de Castilla para la gobernación, ponderando la importancia que había tenido para el gobierno y la administración tanto temporal como espiritual del Imperio español, también expresada en aquellas otras presuntas palabras que Fernández Duro atribuye a Carlos V al enterarse de su fallecimiento: «Se ha muerto un viejecito que me tenía sosegados los Reinos de España con su báculo» (Fernández, 1891: 527 y Paz, 1978, II: 126). Algunos incluso llegan a afirmar que el emperador lamentó más su pérdida que la de la propia reina, pues parece que dijo «mujeres hay muchas, pero Tavera solo hay uno» (Marqués de Lozoya, 1967: IV,159). Para Rumeu de Armas, como político el cardenal fue «después de Cisneros,

12. Archivo Ducal de Medinaceli (ADM), Malagón, leg. 11 n. 52 y Archivo Histórico Provincial de Valladolid (AHPV), Protocolos, leg. 98 (1545), fols. 435-581: Testamento del cardenal (Valladolid, 30 julio 1545). Véase Castán, 1993: 365-378. Sobre este Hospital se han ocupado, principalmente, Zamorano 2002 y Marías, 2007. También Sánchez, 2021c (en prensa).

Ediciones Universidad de Salamanca / అ@@ Stud. his., H. ${ }^{a}$ mod., 43, n. 1 (2021), pp. 229-257 
la figura de mayor significación de la centuria» (Rumeu, 2006: 163). También sintió mucho su muerte el príncipe Felipe porque «le respetaba y amaba como padre» (Salazar, 1603: 352).

\section{BIENES PATRIMONIALES DEL PRELADO EN EL REINO DE SEVILLA}

Juan Pardo Tavera no solo empezó a labrarse un status importante dentro de la Iglesia como prelado en su etapa hispalense inicial, junto a su tío fray Diego de Deza, como hemos podido comprobar, sino que adquirió en el reino de Sevilla una serie de bienes y rentas durante el primer cuarto del siglo XVI, mayoritariamente por vía de compraventa, que iban desde sus casas principales en la calle de Abades de la ciudad de la Giralda, precisamente muy cerca de la propia catedral hispalense $\mathrm{e}^{13}$, y otras moradas rústicas, a un conjunto de donadíos, heredades y cortijos en diversas poblaciones próximas a Sevilla, la mayor parte situadas en el Aljarafe.

Así, en término de Constantina llegó a poseer las tierras de la heredad de Majalimar, el donadío de las Santeras, otro donadío de tierras perteneciente al del Álamo y una haza de tierras llamada de Villaltilla ${ }^{14}$. Por su parte, en término de Villanueva del Camino (o Villanueva del Río), se hizo el obispo Tavera con otro conjunto de tierras como el donadío de la Vega y Antona, haza del donadío de la Cruz frente al arroyo de Galapagar, cuadrejón de tierra del Guadaperos, haza de tierras en el donadío de Antona Pérez que llegaba hasta el barranco del Guadalquivir, donadío de tierras de la huerta de Calillos y otras dos hazas en el mismo donadío - una de ellas en la vega de las Anconillas-, otra haza de tierra conocida por la Dehesilla y otra que iba junto al camino de Cantillana por el arroyo Bermejo, aparte de la haza de Argamasilla y otras más del mismo término ${ }^{15}$.

Además, en término de Utrera, el prelado era propietario del donadío de Pardales, que lo adquirió en 1521 por compraventa a Mencía de Zúñiga por un importe de 1.125.000 maravedís ${ }^{16}$. Posteriormente, lindero con Pardales, adquirió Juan Tavera otro donadío en 1523 a través de la venta de Juan de Valtierra y su mujer, con un

13. Estas casas principales de Sevilla las adquirió Tavera, por vía de compraventa, a los hijos del caballero veinticuatro del concejo hispalense Melchor Maldonado y, efectivamente, se hallaban situadas muy cerca de la catedral (véase ADM, Partido de Sevilla, leg. 1 n. ${ }^{\circ}$ 2). También poseía el obispo otras casas principales en Villanueva del Camino, que habían sido adquiridas por el prelado en compraventa al matrimonio Juan Pérez de Cueva e Isabel Melgarejo, vecinos de Sevilla (véase ADM, Ibidem., leg. 1 n. ${ }^{\circ}$ ).

14. ADM, Partido de Sevilla, leg. 1 n. ${ }^{\circ} 1$.

15. Ibidem.

16. ADM, Ibidem., leg. 1 n. ${ }^{\circ}$ 29: Escritura de compraventa del donadio (Sevilla, 12 abril 1521); y leg. 1 n. ${ }^{\circ}$ 2. Más documentos sobre esta propiedad utrerana en Ibidem., leg. 1 n. ${ }^{\text {os }} 14-19$.

Ediciones Universidad de Salamanca / 요 Stud. his., H. ${ }^{a}$ mod., 43, n. 1 (2021), pp. 229-257 
costo de 14.000 maravedíes ${ }^{17}$. Y «otro pedaço de donadío y tierras de pan llevar», con lindes en los también donadíos de Zarracatinejos, la Goronda (¿hoy La Gironda?) y Casablanca (hoy término de Arahal). En ese mismo año, Juan Tavera también les compra a los propios Juan de Valtierra, María de Zúñiga y los hijos de ambos la mitad del dicho donadío de Zarracatinejos, en el mismo término de Utrera, por un total de 64.000 maravedís ${ }^{18}$.

Igualmente poseía el obispo Tavera en Valencina del Hoyo o del Alcor (hoy Valencina de la Concepción) una suerte de tierras de 17 aranzadas conocida como La Lampa, que había adquirido por compraventa de la familia Saavedra ${ }^{19}$. Y también era propietario el obispo, en término de Las Cabezas de San Juan, de los donadíos de Torralba, que adquirió en enero de 1532 del conde de Miranda por un coste de algo más de dos cuentos de maravedís ${ }^{20}$, y La Palmilla y Piñuela, que habían pertenecido a la Casa de Medina Sidonia ${ }^{21}$.

En cuanto a rentas, en su etapa sevillana poseyó D. Juan Pardo Tavera, entre otras, 17.000 maravedís anuales, de los cuales 14.000 eran en unos cañamares del término de Villanueva del Camino, por compraventa al matrimonio Juan Pérez de la Cueva e Isabel Melgarejo, y los restantes 3.000 sobre unas tierras y viñedos que el mismo Juan Pérez le vendió ${ }^{22}$. También Juan Tavera había adquirido entre 15211522 un tributo perpetuo total de 5.700 maravedís, 3.000 de ellos por un molino de pan, con su batán, llamado el Palomar y situado en las proximidades del río Huéznar - afluente del Guadalquivir - que había adquirido el obispo de Francisco González de Merchante, otros 1.200 «que me vendió Miguel López y su hijo Francisco Rodríguez, vezinos del dicho lugar de Villanueva, sobre unas casas en el dicho lugar» y los restantes 1.500 maravedís sobre un molino llamado el Carretero, en la ribera del Galapagar, comprado al mismo González Merchante ${ }^{23}$.

Poseía también el obispo en la ciudad de Sevilla un juro de 200.000 maravedís anuales compuesto por diversas rentas: 40.000 maravedís en la renta de la buhonería, 20.000 en la de la zapatería, 40.000 en la del mercadillo de tocas y 100.000 maravedís

17. ADM, Ibidem., leg. 1 n. ${ }^{\circ} 31:$ Escritura de venta del donadio ante el escribano Manuel Segura (Sevilla, 11 agosto 1523), según la guarda del documento (falta en el fondo).

18. ADM, Ibidem., leg. 1 n. ${ }^{\circ}$ 54: Escritura de venta ante el mismo escribano público (Sevilla, 12 agosto 1523). Tavera suscribe la compraventa como obispo de Ciudad Rodrigo y presidente de la Chancillería de Valladolid (más documentos sobre esta propiedad en Ibidem., leg. 1 n. ${ }^{\text {os }}$ 50-60). Posteriormente, en 1546, su sobrino compraría la otra mitad del donadío de Zarracatinejos.

19. ADM, Ibidem., leg. 1 n. ${ }^{\circ}$ 2, fol. 6. Véase Franco, 2001: 244.

20. Ibidem., leg. 2 n. ${ }^{\text {s }} 7$ y 8 . Más documentos sobre este cortijo en ADM, Ibidem., leg. 1 n. ${ }^{\text {os }} 61-68$ y leg. 2 n.os $1-18$.

21. Ibidem., leg. $1 \mathrm{n} .^{\circ} 4$ (documento inserto).

22. Ibidem., leg. 1 n. ${ }^{\circ}$ 2, fol. 5.

23. Ibidem., leg. 1 n. ${ }^{\circ} 2$, fol. 5 v. 
en la de lienzos y sayales ${ }^{24}$, aparte de otros 167.500 maravedís anuales de juro al quitar sobre el pescado salado y otras rentas ${ }^{25}$.

Fuera del reino de Sevilla también adquirió el cardenal diferentes bienes, como unas casas en Valladolid y diferentes propiedades en Toledo ${ }^{26}$.

\section{TRANSMISIÓN DE LOS BIENES DEL CARDENAL}

Una buena parte de estos bienes fueron objeto de sendas escrituras de donación suscritas por parte de D. Juan Pardo Tavera, que quedaron vinculados sucesivamente mediante la fórmula de mayorazgo regular, en la persona de su sobrino Arias Pardo de Saavedra (¿1509?-1561) - antes llamado Antón de Deza -, mariscal de Castilla desde 1531 en sucesión de su abuelo materno Gonzalo de Deza, aparte de justicia y alcalde mayor de Sevilla y veinticuatro del concejo de la ciudad, el único hijo varón de su hermano mayor Diego de Deza y su esposa María de Saavedra ${ }^{27}$. La primera escritura a favor de su sobrino la otorgó D. Juan Pardo Tavera en Sevilla el 8 de octubre de $1517^{28}$, siendo obispo de Ciudad Rodrigo y residente en la ciudad hispalense, aún en vida de su hermano ${ }^{29}$, y afectó a los bienes en Constantina y parte de los de Villanueva del Río. La segunda fue dada en Valladolid el 16 de marzo de 1524, siendo obispo de Osma, y se trató de los bienes del término de Utrera, Valencina del Alcor y otra parte de los de Villanueva ${ }^{30}$. Y la tercera escritura fue suscrita por Tavera en Medina del Campo el 1 de julio de 1532, siendo ya arzobispo de Santiago de Compostela, referida particularmente a los bienes del término de Las Cabezas de San Juan (donadío de La Palmilla) y algunas rentas ya comentadas en la ciudad de Sevilla ${ }^{31}$.

Más adelante llegarían nuevas donaciones de bienes del cardenal a su sobrino Arias Pardo, como cuando el mariscal adquirió del emperador Carlos V, en 1542, la

24. Ibidem., leg. 5 n. ${ }^{\circ} 25$.

25. ADM, Ibidem., leg. 3 n..$^{\circ} 52$.

26. Parte de estos bienes se desprende de las rentas que cobraba su heredero universal a principios del siglo XVII (Salazar, 1603: 285-286).

27. Véase nuestra genealogía de la Casa de Malagón =Arias-Pardo=, que ilustra estas páginas (tabla 1$)$.

28. ADM, Partido de Sevilla, leg. 1 n..$^{\circ} 1$.

29. Podría ya encontrarse enfermo Diego de Deza, pues había testado en Sevilla el pasado 5 de septiembre (ADM, Ibidem., leg. 2 n. ${ }^{\circ} 58$ ) y falleció poco tiempo después dentro del mismo año de 1517.

30. ADM, Ibidem., leg. 1 n. ${ }^{\circ} 2$.

31. ADM, Ibidem., leg. 3 n. ${ }^{\circ}$ 52. En la referencia a esta donación, el cardenal llama a Arias Pardo «nuestro sobrino, que se a criado en nuestra cassa e tenemos en lugar de hijo» (véase ADM, Ibidem., leg. 1 n. ${ }^{\circ}$ ). 
encomienda santiaguista desmembrada de Paracuellos del Jarama ${ }^{32}$, en señorío, por un coste de 42.024 .579 maravedís $^{33}$, para lo que su tío le donó aproximadamente la mitad de dicha cantidad ${ }^{34}$.

Ya fallecido el cardenal, con parte de la herencia de su tío, Arias Pardo compró al propio emperador, el 14 de enero de 1548, la antigua encomienda calatrava de Malagón por una cifra cercana a los 56 cuentos de maravedís ${ }^{35}$, siendo así la más valiosa de la treintena de encomiendas que segregó el monarca para poder atender los elevados gastos del Imperio hispánico (Cepeda, 1980: 505). Próxima a Ciudad Real, esta encomienda poseía unos bienes tasados en una cantidad próxima a los 10.000.000 maravedís (Franco, 2001: 270 y 271). Al comprender las villas de Porzuna y Fuente el Fresno, Malagón poseía un vasto patrimonio, con una economía esencialmente ganadera y una serie de tributos y rentas que hacían el señorío apetecible a cualquier noble de la época (Franco, 2001: 274).

Según Salazar y Mendoza, como parte de pago de lo que le costó el señorío de Malagón, entregó el mariscal Arias Pardo la Alcaldía mayor de la Justicia de Sevilla (por valor de más de 24.000 ducados) y la veinticuatría de la ciudad (valorada en 7.000 ducados), más 100.000 maravedís de juro, y 12.000 ducados de la venta de sus casas que tenía en la collación de San Juan de la Palma de la ciudad de Sevilla (Salazar, 1603: 389). Por su parte, los documentos conservados en el Archivo Ducal de Medinaceli y otras fuentes consultadas, precisan los bienes que de los que hubo de desprenderse Arias Pardo, pertenecientes a su patrimonio en el reino de Sevilla y mayoritariamente donados por su tío el cardenal. Principalmente, aclara la cuestión el documento fechado el 28 de octubre de 1548 en la villa de Castelló de Empùries, por el que el emperador Carlos $\mathrm{V}$ le concede a su mariscal de Castilla facultad para vender diversos bienes ${ }^{36}$, entre los que se incluían las casas que poseía en la

32. Sobre el desmembramiento de antiguas encomiendas, véase Moxó, 1961: 327-361. En 1541, el mariscal Arias Pardo de Saavedra compró esta recién desmembrada encomienda de Paracuellos del Jarama con el consiguiente permiso de su comendador, el Marqués de Montesclaros. Véase Archivo Histórico Nacional (AHN), Consejos, leg. 32311, n. ${ }^{\circ}$ 2, fols. 21 y ss.: Memorial ajustado del pleito entre el Fiscal del Consejo y el Duque de Medinaceli, como marido de la Duquesa de Santisteban y Marquesa de Malagón, sobre incorporacibn a la Corona de la villa de Paracuellos, con su fortaleza, jurisdicción, alcabalas y demás derechos. Madrid, 1825 (recogido por Moxó, 1961: 338).

33. ADM, Paracuellos, leg. 2 n. ${ }^{\circ}$.

34. Véase ADM, Malagón, leg. 6 n. ${ }^{\circ}$ 12, documento extractado por Campo, 1997: 740-746. El señorío adquirido de Paracuellos incluía además el coto de Belvis y las dehesas de Viñuelas, El Burguillo, Palomarejo y Cobeña, así como distintas propiedades en Vallecas y Móstoles.

35. ADM, Malagón, leg. 1 n. ${ }^{\circ}$ 21, AHN, Órdenes (Consejo), leg. 4401 y Archivo Histórico de la Nobleza (SNAHN), Frías, caja 1487 n. ${ }^{\circ}$ 1. Véase Campo, 2000: 1795-1816.

36. ADM, Partido de Sevilla, leg. 1 n. ${ }^{\circ} 13$ y leg. 5 n. 17.

Ediciones Universidad de Salamanca / 요 Stud. his., H. ${ }^{a}$ mod., 43, n. 1 (2021), pp. 229-257 
Tabla 1. Genealogía de la Casa de Malagón =Pardo-Tavera=

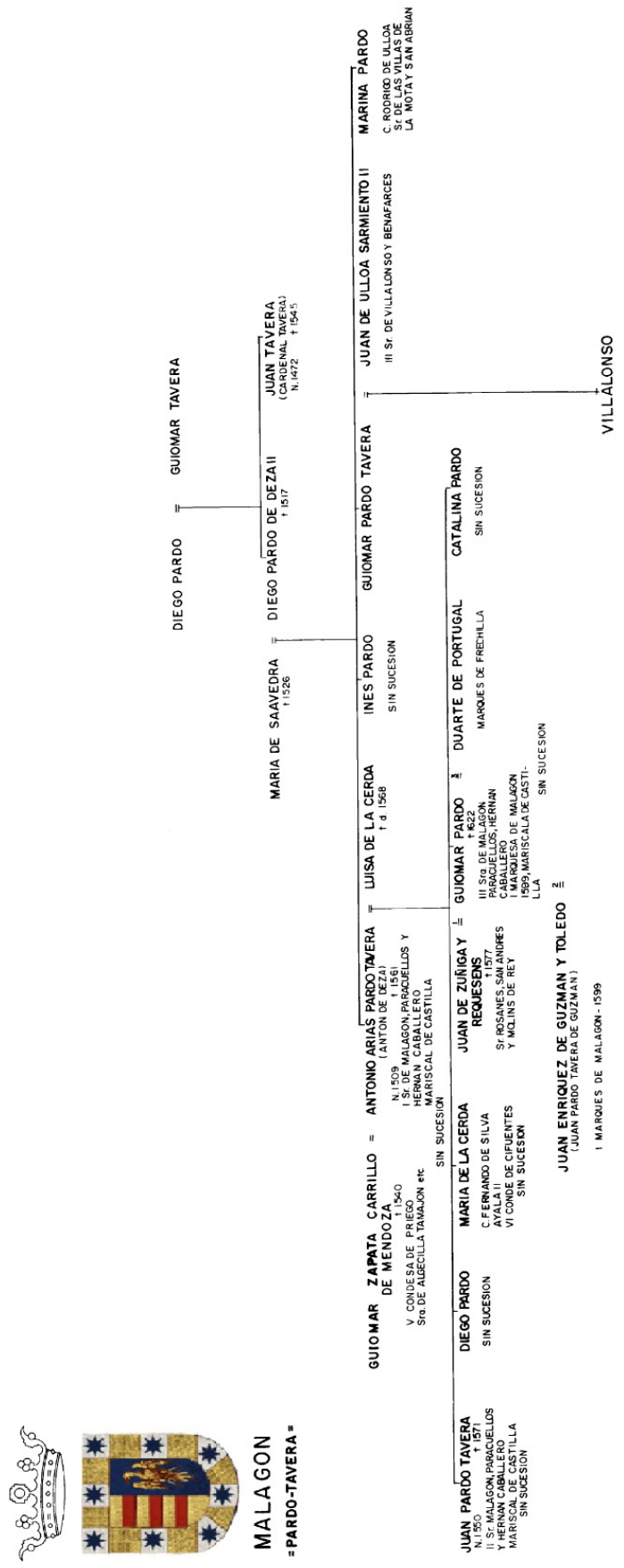

Fuente: Elaboración propia 
calle Abades de Sevilla (confirmada su venta en 155937), la heredad de Majalimar, las haciendas de Villanueva del Camino y Valencina del Hoyo - ésta vendida por entonces a Diego Caballero, mercader y funcionario de la Casa de Contratación (Otte, 2003: 331) - y las aceñas llamadas de las Casas, sitas junto al Guadalquivir en término de Villanueva, para contribuir con su importe a pagar a S.M. el precio en que le vendió la villa y encomienda de Malagón. Además, pierde Arias Pardo el oficio de la Alcaldía de Sevilla, que había heredado de su abuelo materno Gonzalo de Saavedra, siendo compensado por Carlos V con 10.000 ducados (Franco, 2001: $270)^{38}$. Con el mismo fin de saldar su deuda sobre Malagón, al año siguiente, el 27 de octubre de 1549, Arias Pardo vende a Alonso Pesguer un juro de 40.000 maravedís anuales sobre el almojarifazgo mayor de Sevilla y otras rentas de la ciudad ${ }^{39}$. También por entonces estipula el mariscal la venta a Diego González de Medina de un juro de 50.000 maravedís sobre las alcabalas de las carnicerías de Sevilla ${ }^{40}$, rentas que Arias Pardo ya había comprometido para entregarlas a la Corona como parte del pago aplazado (Campo, 1997: 115).

Arias Pardo tomó así posesión, como señorío pleno, de una antigua encomienda situada en pleno Campo de Calatrava que no había resultado nada barata sino todo lo contrario. Aspiraría a ser señor de vasallos y lo había conseguido. Y era momento de garantizar la sucesión de los nuevos bienes adquiridos en el mayorazgo familiar (Paracuellos y Malagón, especialmente), lo que hizo el mariscal el 26 de julio de $1557^{41}$, imponiendo el apellido Pardo-Tavera y armas al heredero (en recuerdo de su tío, el cardenal), un mayorazgo que confirmará después en su último testamento.

Previamente, en Toledo, el 11 de junio de 1560 le otorga el rey Felipe II - a petición del propio Arias Pardo - real provisión facultando a su mariscal de Castilla para subrogar los bienes que poseía en el reino de Sevilla por donación y vínculo de su tío D. Juan Pardo Tavera, desde cuando este era obispo de Ciudad Rodrigo y de Osma, a la vez que para ampliar el mayorazgo incluyendo las villas de Malagón y Porzuna ${ }^{42}$.

No solo estas, sino también Paracuellos de Jarama con sus posesiones anejas, fueron incluidas finalmente en el citado mayorazgo que ratificó Arias Pardo el 9

37. ADM, Partido de Sevilla, leg. 5 n. 17 (Sevilla, 16 agosto 1559). En la autorización solicitada al rey para la venta de dichas casas, que se tasa en 40.000 ducados, se incluye también la heredad de Valencina del Alcor.

38. Dicha cantidad la abonó la propia ciudad de Sevilla.

39. ADM, Partido de Sevilla, leg. 9 n. ${ }^{\circ}$ 46. En concreto, aparte de esos 40.000 maravedís, otros juros de heredad de 30.000 maravedís de las mercadurías, de 5.000 de la renta del pescado fresco y de 5.000 del diezmo del aceite de las puertas.

40. ADM, Partido de Sevilla, leg. 5 n. 33 (copia simple, s.f. [1549]). Aunque el documento no está datado, la fecha se deduce al indicarse en su texto que el cobro del juro tendría efecto a partir de $1^{\circ}$ de enero del siguiente año de 1550.

41. ADM, Malagón, leg. 6 n. ${ }^{\circ}$ 9. Véase también ADM, Paracuellos, leg. 7 n. ${ }^{\circ} 60$.

42. ADM, Partido de Sevilla, leg. 1 n. ${ }^{\circ} 2$. 
de enero de 1561, al tiempo de ordenar su testamento ${ }^{43}$. Cinco días después fallecía en Toledo.

El beneficiario de esta rica herencia, por la línea de primogenitura que imponía este mayorazgo regular, sería el primogénito - llamado como el cardenal, Juan Pardo Tavera - de los 5 hijos habidos del segundo matrimonio del mariscal con $\mathrm{D}^{\mathrm{a}}$. Luisa de la Cerda, hija del segundo Duque de Medinaceli D. Juan de la Cerda. Sin embargo, Juan Pardo Tavera (1550-1571), II Señor de Malagón, Paracuellos y Fernán Caballero, además de mariscal de Castilla, no pudo disfrutar mucho tiempo de este mayorazgo pues apenas vivió 21 años, siendo su madre quien se ocupase de la administración de los bienes (Sánchez, 2016a: 211). Previamente incluso Da . Luisa de la Cerda añadió al mayorazgo, con facultad real, gran parte de sus pertenencias por escritura dada el 23 de octubre de 1564, que ella misma ampliaría diez años más tarde incorporando la villa de Fernán Caballero ${ }^{44}$, que había adquirido - según Salazar y Mendoza - en trueque con el rey Felipe II por la dehesa de Palomarejo, cerca de El Pardo, que «es de tanta recreación que la mandó cercar el Rey para la suya» (Salazar, 1603: 388).

Muerto el joven Juan Pardo, soltero y sin descendencia, el 22 de octubre de 1571, otra hija de Arias Pardo y de Luisa de la Cerda, llamada Guiomar Pardo Tavera $(† 1622)$, sucede en el mayorazgo también en edad juvenil ${ }^{45}$. Tres años después de esta herencia, la señora de Malagón y Paracuellos contraía nupcias con Juan de Zúñiga Requesens, señor de Martorell, un matrimonio que se truncaba al poco tiempo por muerte de este; y en 1578 casaba de nuevo $\mathrm{D}^{\mathrm{a}}$. Guiomar con Juan Enríquez de Guzmán y Toledo, hijo de los Condes de Alba de Liste (véase Sánchez, 2016a: 211). A estos, el 16 de febrero de 1599, el recién entronizado monarca Felipe III les concedió conjuntamente -a él con nombre de Juan Pardo, precisamente por imperativo del mayorazgo - el título de primeros Marqueses de Malagón ${ }^{46}$, elevándose de esta forma a rango de marquesado el antiguo dominio calatravo. Sin embargo, ninguno de ambos matrimonios, ni un tercero contraído en 1606 por $\mathrm{D}^{\mathrm{a}}$. Guiomar con el marqués de Frechilla Duarte de Portugal ${ }^{47}$, le dieron a la Marquesa de Malagón descendencia alguna, extinguiéndose con ella en 1622 la línea de los Arias Pardo-Tavera.

43. ADM, Malagón, leg. 6 n. ${ }^{\circ} 11$.

44. Véase ADM, Inventario del Partido de Malagón, fols. $205 \mathrm{v}^{\mathrm{o}}-206 \mathrm{v}^{\mathrm{o}}$. La adquisición de Fernán Caballero, en el mismo año de 1574, en ADM, Malagón, leg. 2 n. 31 (guarda del doc.).

45. Véase ADM, Medinaceli - Desvinculación, leg. 287 n. ${ }^{\circ}$ 19: Informe bistórico sobre la sucesión del mayorazgo de la Casa de Malagón, redactado por Luis de Salazar. Madrid, 6 de mayo de 1723 (transcrito en Campo, 1997: 737-739).

46. ADM, Archivo Histórico (Títulos), leg. 272 n..$^{\circ} 34$ (antigua caja 2 n. ${ }^{\circ} 34-R$ ).

47. Véase ADM, Malagón, leg. 10 n. ${ }^{\circ} 28$ : Capítulos matrimoniales para el enlace. Madrid, 17 abril 1606.

Ediciones Universidad de Salamanca / @®@@ Stud. his., H. ${ }^{a}$ mod., 43, n. 1 (2021), pp. 229-257 
Esta anómala circunstancia, tras la resolución de una serie de pleitos en cuyo tiempo el marquesado de Malagón quedó vacante, fue la que hizo recaer este estado y sus señoríos anexos de Fernán Caballero y Paracuellos de Jarama en Diego de Ulloa Sarmiento (†1647), II Conde de Villalonso, como más propincuo varón y con mejor derecho a la sucesión al descender de una tía de la última titular de esos estados, también llamada $\mathrm{D}^{\mathrm{a}}$. Guiomar Pardo, hermana de Arias Pardo y esposa de su bisabuelo, el tercer señor de Villalonso y Benafarces D. Juan de Ulloa Sarmiento ${ }^{48}$. Se aplicaba así el orden de sucesión establecido, allá por 1517, por el obispo Tavera, que no era otro que el regular del mayorazgo, con la herencia a la línea tercera de la prole de Diego Pardo de Deza, hermano de D. Juan Tavera.

Sin embargo, no tuvo ninguna posteridad el heredero D. Diego de Ulloa del matrimonio que contrajo con $\mathrm{D}^{\mathrm{a}}$. Antonia de Benavides, una hija de los VII Condes de Santisteban del Puerto, ni de otro anterior con su prima $\mathrm{D}^{\mathrm{a}}$ Magdalena Sarmiento y Ulloa ${ }^{49}$. Por esa razón, a su muerte en 1647 , su hermana $\mathrm{D}^{\mathrm{a}}$. Francisca de Ulloa Sarmiento se convertía desde entonces en III Marquesa de Malagón, III Condesa de Villalonso y señora de Paracuellos, Benafarces y Fernán Caballero, entre otros dominios.

Para entonces esta señora había contraído nupcias, desde 1609, con su primo hermano D. Gaspar Juan Arias de Saavedra, V Conde del Castellar y señor del Viso, y había enviudado de é ${ }^{50}$. En consecuencia, todos estos estados patrimoniales de los extintos Pardo-Tavera y los Ulloa pasarían al primogénito de estos, D. Fernando Miguel Arias de Saavedra y Ulloa, agregados a la Casa de Castellar, titulándose así VI Conde de Castellar, III Marqués de Malagón y IV Conde de Villalonso, además de mariscal y alfaqueque mayor de Castilla. Este había casado en 1632 con Da ${ }^{a}$. Catalina de Acevedo ${ }^{51}$ y, en ausencia de varón del matrimonio - pues D. Fernando Miguel fue el último en línea de primogenitura-, le sucedía su hija $\mathrm{D}^{\mathrm{a}}$. Teresa María Arias de Saavedra, esposa a su vez desde 1664 de D. Baltasar de la Cueva y Enríquez de Cabrera ${ }^{52}$, un hijo de los duques de Alburquerque que fue fiscal del Real Consejo de las Órdenes, consejero del Real y Supremo Consejo de Indias y gentilhombre de Cámara, además de virrey del Perú entre 1674 y 1678 (véase Fernández de Bethencourt, X, 1920: 309-313) ${ }^{53}$.

Sucedió a estos el primogénito del matrimonio D. Fernando Joaquín de la Cueva Arias de Saavedra ( $† 1721)$ quien, aunque casado con María Antonia Ruiz de Castro Centurión, ante su temprana muerte sin descendencia en 1721, el mayorazgo pasó

48. Véase ADM, Medinaceli - Desvinculación, leg. 287 n. ${ }^{\circ} 19$.

49. Véanse RAH, Col. SyC, n. ${ }^{\text {ss }} 13118,62693,56263,52987$ y 73174 del referido inventario.

50. Véase ADM, Medinaceli - Desvinculación, leg. 287 n. ${ }^{\circ} 19$ y ADM, Castellar, leg. 5 n. ${ }^{\circ} 15$.

51. ADM, Castellar, leg. 5 n. ${ }^{\circ}$ 16: Capítulos matrimoniales para este enlace ( 6 de noviembre 1632).

52. ADM, Castellar, leg. 5 n. ${ }^{\circ}$ 25: Capitulaciones matrimoniales.

53. Sobre su virreinato, véase Hanke (ed.), 1978: V, 37-178. 
a su única hermana $\mathrm{D}^{\mathrm{a}}$. Ana Catalina de la Cueva Arias de Saavedra (1684-1735), titulada desde entonces VI Marquesa de Malagón, IX Condesa del Castellar y VII de Villalonso, otros títulos aparte. Esta señora era esposa, desde 1707, del X Conde de Santisteban del Puerto - y luego I Duque de aquel estado-, D. Manuel de Benavides y Aragón, por lo que aquellos títulos y dominios se incorporaron a la Casa de los Caudillos Mayores del reino de Jaén, que eran estos Benavides ${ }^{54}$.

En consecuencia, por esta alianza en adelante quedaba agregado el marquesado de Malagón, con la mariscalía de Castilla, cuyos titulares seguían poseyendo una administración en Sevilla con los bienes de aquel antiguo reino, a la Casa de Santisteban del Puerto, arrastrando consigo el condado de Castellar de los Arias de Saavedra y el condado de Villalonso de los Ulloa. Y todos juntos, en dicha Casa de Santisteban, se incorporarían a la ducal de Medinaceli a fines del mismo siglo XVIII al contraer matrimonio en 1764 los entonces herederos de las respectivas casas nobiliarias. Por un lado, Da Joaquina María de Benavides y Pacheco (1746-1805), Marquesa de Solera y luego III Duquesa de Santisteban del Puerto - nieta del citado D. Manuel-y, por otro, D. Luis María Fernández de Córdoba y Gonzaga (17491806), Marqués de Cogolludo y futuro XIII Duque de Medinaceli (Sánchez, 2015: 60-62). El heredero de este vasto patrimonio sería el hijo de ambos, D. Luis Joaquín Fernández de Córdoba y Benavides (1780-1840), XIV Duque de Medinaceli y IV de Santisteban del Puerto, IX Marqués de Malagón y tantos otros títulos, a quien cogió la abolición de los mayorazgos y del régimen señorial con la implantación del Régimen Liberal en España durante el primer cuarto del siglo XIX, consumada en 1841 (véase Sánchez, 2017: 331), por lo que los dominios aquí tratados dejaron de tener el vínculo familiar, convertidos para los herederos en bienes de libre disposición.

\section{EL ARCHIVO SEVILLANO DEL CARDENAL TAVERA EN PODER DE LA CASA DE MALAGÓN}

El Archivo originario de esta documentación patrimonial de D. Juan Pardo Tavera en el antiguo reino de Sevilla se gestó en la ciudad de la Giralda, emplazándose primero con toda seguridad en las casas que tenía el por entonces canónigo, chantre, provisor y oficial del cabildo catedralicio hispalense, además de vicario general de aquel arzobispado.

Más adelante, una de las casas que conservó en la ciudad andaluza Arias Pardo y, tras él sus sucesores, debió de servir de sede de la administración de los bienes de los marqueses de Malagón en el reino de Sevilla, donde quedó custodiada la documentación durante el tiempo en que fue efectiva dicha contaduría. Mientras tanto, los marqueses de dicho estado manchego tenían el Archivo de su estado principal

54. Un estudio muy completo de esta casa nobiliaria en Sánchez, 2015.

Ediciones Universidad de Salamanca / @®@@ Stud. his., H. ${ }^{a}$ mod., 43, n. 1 (2021), pp. 229-257 
en la propia villa manchega de Malagón, junto con los documentos del señorío colindante de Fernán Caballero (Sánchez, 2021a), mientras que el otro señorío anexo de Paracuellos de Jarama mantenía su documentación en este lugar próximo a Madrid (Sánchez, 2021b).

Y, como quedó dicho, al contraer matrimonio $\mathrm{D}^{\mathrm{a}}$. Ana Catalina de la Cueva Arias de Saavedra con D. Manuel de Benavides, X Conde - y luego I Duque - de Santisteban del Puerto, al heredar ella de su hermano el patrimonio familiar en 1721, se incorporaban a dicha Casa de Santisteban el marquesado de Malagón, además de los condados de Castellar y Villalonso. A partir de entonces, la concentración archivística de los numerosos fondos de tales casas nobiliarias estaba más cercana. Solo habría que esperar unos años para que todos esos fondos documentales, dispersos por la geografía peninsular, junto con otros que también poseían estos Benavides por diversos estados patrimoniales, fueran reclamados por sus titulares para incorporarse al Archivo General de la Casa de Santisteban del Puerto en Madrid (Sánchez, 2015).

\section{INTEGRACIÓN DEL FONDO DOCUMENTAL EN UNIDADES ARCHIVÍSTICAS SUPERIORES: ORGANIZACIÓN Y DESCRIPCIÓN}

Cuando el marquesado de Malagón, con el condado de Villalonso ${ }^{55}$, se incorpora a mediados del mismo siglo XVII a la Casa de Castellar ${ }^{56}$, e incluso más tarde cuando todos esos títulos, estados y propiedades se agregaron en las primeras décadas del siglo XVIII a la Casa de Santisteban del Puerto no parece que sus titulares tuvieran previsto aún ningún tipo de medidas tendentes a la concentración de los dispersos depósitos documentales, al menos en un primer momento. Sin embargo, poco después la política de concentración archivística de los Benavides no se haría esperar, tal vez emulando el imperante centralismo borbónico.

Estos condes - duques a partir de 1739- tenían por entonces su morada principal en Madrid, en la casa-palacio o "Casa Grande» que poseía la familia frente a la iglesia de San Pedro el Viejo, esquina a la calle del Nuncio ${ }^{57}$. Y, por entonces, los Santisteban ordenan la transferencia hasta aquel edificio madrileño de todos y cada uno de los numerosos Archivos que la Casa tenía repartidos por sus cuantiosos estados señoriales. De ahí que, entre 1720 y 1751, principalmente por los años treinta, fueran llegando paulatinamente hasta el depósito documental de aquel inmueble los diferentes Archivos de esos diversos estados agregados ${ }^{58}$.

55. El Archivo de este condado castellano-leonés radicaba entonces en la ciudad de Toro.

56. La documentación del condado de Castellar de la Frontera se emplazaba, desde el siglo XV, en el castillo-fortaleza de esta villa gaditana próxima a Gibraltar.

57. Sobre esta casa-palacio, véase ADM, Santisteban, leg. 28 n. ${ }^{\text {os }} 12$ a 30. Cfr. Sánchez, 2015: 109-112.

58. Véase todo el proceso de concentración archivística de los diversos fondos en Sánchez, 2015: 103-108. El 2 de agosto de 1735 el aún conde de Santisteban D. Manuel de Benavides

Ediciones Universidad de Salamanca / @®@@ Stud. his., H. ${ }^{a}$ mod., 43, n. 1 (2021), pp. 229-257 
El primer conjunto documental que tomó rumbo hasta la capital del reino fue precisamente el del estado principal de Santisteban del Puerto y los de sus señoríos próximos y agregados de Solera, Espelúy e Ibros, desde tierras jiennenses, lo que resulta del todo lógico. Estos fondos formarían, por tanto, el embrión o núcleo forjador del Archivo General de la Casa. Los restantes integrantes se irían agrupando paulatinamente al depósito archivístico e incluso algunos se resistirían a llegar por el momento.

A continuación, los siguientes fondos que llegan a Madrid fueron precisamente los de los estados de $\mathrm{D}^{\mathrm{a}}$. Ana Catalina de la Cueva Arias de Saavedra, la esposa del conde Manuel de Benavides, entre ellos los del marquesado de Malagón y de la administración de los bienes del Partido de Sevilla, que ya se encuentran en la capital del reino, junto al de Santisteban, al iniciarse la tercera década del mismo siglo XVIII ${ }^{59}$.

Más adelante, a raíz de la unión de las Casas de Santisteban del Puerto y Medinaceli, se propiciaría la ulterior integración de ambos Archivos generales en un depósito único. Habría que esperar, no obstante, a que pasara el convulso período de la Guerra de la Independencia española (1808-1814), durante el que estos duques fueron declarados proscritos y sus bienes confiscados por Napoleón, para que el heredero de ambas casas D. Luis Joaquín Fernández de Córdoba y Benavides ordenara la transferencia del Archivo de Santisteban a la sede del Archivo Ducal de Medinaceli, ubicado en el majestuoso palacio que estos tenían en el Paseo del Prado, una concentración de fondos - como el del marquesado de Malagón con el fondo del Partido de Sevilla - que se produjo en 1818.

$\mathrm{Y}$, en adelante, la documentación que aquí tratamos ya no abandonaría el Archivo Ducal de Medinaceli, tanto en Madrid (1818-1961) como después retornando a Sevilla con sede en la «Casa de Pilatos» (1961-1995) y, por último, en Toledo —desde 1995-, dentro del Palacio Tavera (antiguo Hospital de San Juan Bautista), donde hoy permanece.

\subsection{Organización y descripción documental}

El principal artífice inicial de las tareas orgánicas y descriptivas sobre los fondos archivísticos de la Casa de Santisteban del Puerto, al que quedó inicialmente integrado el del Partido de Sevilla de los marqueses de Malagón, fue el archivero Manuel Antonio Brochero (1735-1773), como se ha dado a conocer (Sánchez, 2015: 113-139 ${ }^{60}$. Conocemos su labor gracias a un informe que elaboró a requerimiento del marqués de Solera, heredero de la Casa, para remitirlo a Italia al conde D. Manuel

emite una orden desde Nápoles para que los administradores de sus estados (bajo cuya custodia aún quedaban sus respectivos fondos) remitiesen las escrituras a Madrid (ADM, Santisteban, leg. 39 n. ${ }^{\circ} 2$ expd. 2$)$.

59. Véase ADM, Ibidem.

60. Más adelante, según el mismo autor, prosiguió estas labores en el depósito archivístico en la misma fase inicial el también archivero D. Manuel de Terán (1783-1802). 
de Benavides, su padre, donde por entonces servía al rey de Nápoles (futuro Carlos III de España), para mantenerle informado ${ }^{61}$. Dicho informe, autógrafo y firmado por Brochero, aunque carece de fecha, debió haberlo realizado entre 1735 y $1737^{62}$ y de su tenor se desprende el estado de disposición documental de los fondos del depósito madrileño de los Santisteban por aquellas fechas señalando, al respecto, que

El estado de Malagón se compone de siete papeleras ó cajones [...], dos ocupa el partido de Paracuellos como caueza de esta Casa; otros dos ocupa el partido de Malagón; otros dos ocupa el partido de dicha ciudad de Seuilla por hauer en ella vienes [sic] pertenecientes a Castellar y Malagón; y el otro ocupa el partido de Toledo ${ }^{63}$.

Esta mención al fondo Partido de Sevilla de la Casa de Malagón viene a confirmarnos que este fondo sevillano, como el propio archivo marquesal de Malagón, ya habían llegado - juntos o por separado - a la Casa Grande madrileña de los Santisteban en esos años. Había, pues, una sección Sevilla (entre las 17 que componían por entonces el Archivo Ducal de Santisteban, una para cada uno de los estados y administraciones señoriales $)^{64}$, cuya documentación ocupaba dos cajones o «papeleras» del depósito ${ }^{65}$.

En estricta aplicación del principio de respeto a la procedencia de los fondos, quedó conformado el organigrama del Archivo General de la Casa de Santisteban, procediendo el archivero Brochero describiendo («de mi puño») a la clasificación archivística de la mayoría de las secciones (entre las que se incluye la de Sevilla que

61. Al ocupar, en 1734, el trono de Nápoles el infante don Carlos (como Carlos VII de Nápoles), el entonces conde de Santisteban D. Manuel de Benavides - por recomendación de la reina Isabel de Farnesio, madre del nuevo rey napolitano- acudió a Nápoles como tutor del joven monarca y allí será su principal ministro hasta 1738, año en que regresa a Madrid.

62. ADM, Santisteban, leg. 39 n. 2 expd. 2. Transcrito el informe en Sánchez, 2015: 267-268.

63. Ibidem., fol. 2. En definitiva, en esas unidades de instalación se encontraba la documentación del marquesado de Malagón, el señorío de Paracuellos de Jarama, los bienes de la administración de Sevilla y los bienes que tenían los Pardo-Tavera en Toledo.

64. Además de esta sección Sevilla, ocupando esos dos cajones, existían estas otras en el depósito: tres secciones del estado del Castellar (El Viso, Castellar y otra también denominada Sevilla o Partido de Sevilla), cinco del estado de la Casa principal de Santisteban del Puerto (Solera, Santisteban, Espelúy, Ibros y Jaén), tres del estado de Las Navas (Villafranca, Las Navas y Ávila), otra del condado de Villalonso, una más del condado de Medellín, aparte las cuatro ya referidas del estado de Malagón (Paracuellos, Malagón, Toledo y la propia Sevilla que nos ocupa). En definitiva, podemos comprobar que había entonces en el depósito de la Casa de Santisteban dos secciones denominadas «Sevilla», una correspondiente a los bienes de la administración de los Arias de Saavedra, condes de Castellar, y la otra la de los bienes de la Casa de Malagón que aquí venimos tratando, lo que va a acarrear una subsanación inmediata por parte del archivero.

65. Pronto se redujeron las secciones a 15, al integrarse los papeles del estado de Castellar de la administración de Sevilla en la sección El Viso, por un lado, y los de la administración de Toledo de los Pardo-Tavera en la sección Malagón, por otro. Así quedaron resueltas las dificultades que entrañaba la duplicidad de secciones con la misma denominación.

Ediciones Universidad de Salamanca / @@ Stud. his., H. ${ }^{a}$ mod., 43, n. 1 (2021), pp. 229-257 
venimos tratando), pieza a pieza, cada una en su envoltura, donde anotó las regestas o extractos ${ }^{66}$. Pese a la amplitud desorbitada de algunas de esas regestas, que se convierten en casi una transcripción del documento ${ }^{67}$, en general, estas relaciones de contenido adolecieron de alguna imprecisión ${ }^{68}$.

A continuación, el archivero formó series con la documentación de cada fondo, unas series por lo general demasiado ambiguas, genéricas y concisas o poco aclaratorias (títulos de dominio, títulos de posesión, pertenencias de..., varios, etc.), junto a otras más precisas (juros, censos, casas, cortijos y heredades, etc.).

Luego se procedió a la ordenación de los documentos siguiendo un criterio cronológico, que se combinó con otro numérico, pues cada escritura así ordenada recibió un número correlativo dentro de su serie. Y se formaron legajos con los documentos ordenados, que también se enumeraron correlativamente.

Fruto de este trabajo orgánico desarrollado por Brochero en el depósito documental de los Benavides en Madrid fue la elaboración de 15 tomos inventarios, donde quedó refrendada toda su tarea archivística. La finalidad de estos inventarios nos la presenta el propio Manuel Antonio Brochero indicándonos que tenían esta triple funcionalidad:

...para el régimen del Archivo, para la busca de papeles; para el de la Contaduría, para que la conste la hacienda; y para que respectivamente sepa la Secretaría los patronatos, provisiones y regalías de la Casa ${ }^{69}$.

Concretamente el inventario que aquí nos interesa es el que lleva por título Libro del Partido de Sevilla que, aunque carece de fecha, fue elaborado y escrito por Brochero en torno a 1735 . Forma un tomo con formato de marca mayor, que está encuadernado en tafilete marrón «con sus fundas de vadana [sic]» y con grecas y decoración vegetal grabada en oro fino, al clásico estilo barroco español, y lleva

66. ADM, Santisteban, leg. 39 n. ${ }^{\circ} 2$ expd. 2. Informe del estado del Archivo en torno a 1735. Añade Brochero en este documento autógrafo suyo: «haviendo leydo más de 50.000 ojas [...] para sacar la substancia». Estas regestas descriptoras solían ser bastante amplias, lo que en muchos casos le obligó a utilizar doble papel como envoltura o «guarda» de la unidad documental.

67. Véase ADM, Partido de Ávila, leg. 6 n. ${ }^{\circ}$ 13. Cfr. Inventario del Partido de Ávila, 513-640 (regesta del doc. aludido).

68. Ello obligó en el futuro a renovar estas regestas imprecisas de Brochero, mejorándolas de contenido (véase ADM, Partido de Ávila, 16-51, nota archivística que encabeza la serie) y, además, dejó secuelas en los inventarios en forma de tachaduras y adiciones (véase Libro del Estado de Medellín, 1-7; o Libro del Partido de Ávila, 1323).

69. ADM, Santisteban, leg. 39 n. 2 expd. 2. Es decir, estos instrumentos de descripción del Archivo General de Santisteban constituían una auténtica herramienta de primera mano para la gestión de la propia Casa Ducal en sus tres principales órganos administrativos: Secretaría, Contaduría y Archivo. Hecho que podemos generalizar y aplicar en su totalidad a cualquier Casa de la alta nobleza española.

Ediciones Universidad de Salamanca / @®@@ Stud. his., H. ${ }^{a}$ mod., 43, n. 1 (2021), pp. 229-257 
broche-cierre metálico. El inventario se compone de 632 páginas manuscritas y se inicia con el escudo de armas de los Arias Pardo pintado sobre pergamino, obviamente en cuanto que el fondo documental que describe se refiere exclusivamente al patrimonio que poseían los marqueses de Malagón en la ciudad de Sevilla y su partido. A este escudo (erróneamente timbrado con corona ducal) le sigue el índice de materias en las que queda estructurado el inventario. El manuscrito, como todos los de la serie de Brochero, se concibió además como si se tratase de un doble inventario pues se le adjudicaba una buena proporción de páginas del tomo, a partir en este caso de la que lleva el número 533, como segunda parte del propio inventario, que se iniciaba con la misma tabla de contenido o índice de materias que precedía a todo el volumen, diferenciándose obviamente tan solo en los números de las páginas asignadas a cada título. Esta segunda parte del inventario no hubo necesidad de utilizarla pues la ampliación del fondo se registró en la primera parte del tomo (fundamentalmente entre las páginas 517 y 520).

Todo hace indicar que a mediados del siglo XVIII ya había culminado Manuel Antonio Brochero la labor orgánica de los fondos de todos los estados de la Casa de Santisteban del Puerto, incluidos los del Partido de Sevilla y marquesado de Malagón, excepción hecha de los del condado de Cocentaina que no llegaron a Madrid hasta el año 1751 por circunstancias especiales.

La valoración final a todo su trabajo orgánico en el Archivo General de los Santisteban podemos calificarla solo de aceptable. En el debe de Brochero queda fundamentalmente la creación, en la clasificación, de series muy vagas e imprecisas (que serían, más adelante, parcialmente corregidas por otros archiveros) ${ }^{70}$. Las regestas que compuso fueron tan extensas, en la mayoría de los casos, que hacían perder el hilo del extracto (cantidad informativa que, al menos aquí, no es sinónimo de calidad en la transmisión de datos). Por otro lado, el sistema de orden impuesto en la organización documental no sirvió para mantener el rigor cronológico deseado en la disposición de los fondos, aunque este criterio cronológico era el que se había buscado previamente. En su disculpa cabe indicar la inmensa tarea que realizó, cuantitativamente hablando, por sí solo y con escasísima ayuda ${ }^{71}$.

Una vez concluida la etapa de Brochero como archivero en 1773, ese mismo año el Archivo Ducal de Santisteban quedó reglamentado por las Instrucciones dadas

70. Esto repercutió en que, aún en nuestros días, resulte complejo a veces localizar un determinado documento dentro del fondo.

71. Brochero no contó con un oficial, ni siquiera con algún copista. Él es quien describe todos y cada uno de los documentos, quien escribe de su puño los 15 inventarios que compuso, incluido el de Medellín, y quien transcribe muchos diplomas que lo requerían. Fue escasa, por tanto, la ayuda que recibió de la Casa Ducal y mucho lo que se le exigió, al contrario -por ejemplo- que a su sucesor en el cargo.

Ediciones Universidad de Salamanca / @®@@ Stud. his., H. ${ }^{a}$ mod., 43, n. 1 (2021), pp. 229-257 
desde Aranjuez, el 8 de junio de ese mismo año ${ }^{72}$ por D. Antonio de Benavides, VII Marqués de Malagón y II Duque de Santisteban, al poco de nombrar nuevo archivero mayor a D. José Manuel de la Vega (1773-1782) ${ }^{73}$, una fase transitoria en el depósito desde el punto de vista orgánico ${ }^{74}$.

Con el relevo en la jefatura de la Casa de Santisteban-Malagón, en 1782, al suceder $\mathrm{D}^{\mathrm{a}}$. Joaquina María de Benavides y Pacheco, también debió declinar la gestión de J. M. de la Vega a cargo del Archivo, ascendiendo en el oficio D. Manuel de Terán (1783-1802), que era oficial del mismo desde $1780^{75}$. Este sería el artífice de la conclusión y complementariedad de la organización documental de los fondos del Archivo (véase Sánchez, 2015: 133-139), con innovaciones intranscendentes, si bien su labor apenas afectó al fondo del Partido de Sevilla, que se mantuvo por entonces en el estado en que lo había dejado Brochero.

Entrado el siglo XIX, con la agregación de la Casa de Santisteban a la de Medinaceli personalizada en el duque heredero D. Luis Joaquín Fernández de Córdoba y Benavides, además IX Marqués de Malagón, se va a producir un intento de homogeneización de los fondos de un Archivo y otro (Santisteban y Medinaceli), ambos en Madrid, sobre todo a raíz de la transferencia del primero, en 1818, al palacio de los Medinaceli en el Paseo del Prado ${ }^{76}$. Por orden ducal de 4 de abril de ese año, el Archivo de Santisteban se incorporaba así al de Medinaceli, bajo la dirección única del archivero D. Juan Gil de Arana, ocupando una dependencia aparte, aledaña al antiguo depósito, en el propio palacio del Prado ${ }^{77}$.

Ya a fines del mismo siglo XIX, se va a consumar la organización total de los fondos y su descripción general. Así, cuando se realizó un recuento global de la documentación de los depósitos archivísticos de los duques de Medinaceli (Sánchez, 2014: 97) por parte del archivero-bibliotecario de D. José María Octavio de Toledo en $1886^{78}$, el fondo concreto del Partido de Sevilla de la Casa de Malagón se componía de 29 legajos, y se hallaba custodiado en tres papeleras (las enumeradas del 10 al 12 de la Casa de Santisteban), tal como aquí recogemos.

72. ADM, Santisteban, leg. 39 n..$^{\circ}$ expd. 5: doc. inserto en la ratificación de 26 de marzo de 1799, que tuvo dicha Instrucción). Véase Sánchez, 2015: 140-144.

73. Una comparación de este reglamento con otro del Archivo Ducal de Medinaceli, elaborado el mismo año, en Sánchez, 2016b.

74. Este archivero, en realidad, aportó muy poco (Sánchez, 2015: 131-133).

75. ADM, Santisteban, leg. 39 n. ${ }^{\circ} 2$ expds. 5 y 7.

76. Más datos en Sánchez, 2015: 149-160.

77. Arana fue un leal servidor de la Casa pues defendió los Archivos y todo el patrimonio ducal como si fuera suyo durante los difíciles años de la guerra de la Independencia (véase Sánchez, 2015: 152-167).

78. El Archivo Ducal de Medinaceli, en su conjunto, estaba entonces integrado en 42 secciones, con 3.864 legajos, 502 libros y 37 documentos sueltos, que se custodiaban en las 460 papeleras del depósito. 
Tabla 2. Disposición del fondo del Partido de Sevilla en el Archivo Ducal de Medinaceli (1886)

\begin{tabular}{|c|c|c|c|c|}
\hline SigNATURA & SERIES & $\begin{array}{c}\text { N. }{ }^{\circ} \\
\text { LEGAJOS }\end{array}$ & $\begin{array}{c}\text { N. }^{\circ} \\
\text { Docs. } \\
\text { SuEltos }\end{array}$ & $\begin{array}{l}\text { N. }{ }^{\circ} \\
\text { LiBRos }\end{array}$ \\
\hline Papelera 10 & $\begin{array}{l}\text { Papeles pertenecientes á Sevilla (Leg. } \\
1^{\circ} \text { á } 6^{\circ}, 8^{\circ} \text { á } 14 \text { y uno sin numeración) }\end{array}$ & 14 & & \\
\hline Papelera 11 & $\begin{array}{l}\text { Idem (Leg. 7, } 15 \text { á 17, } 19 \text { á } 25 \text { y uno } \\
\text { sin numerar) }\end{array}$ & 12 & & \\
\hline Papelera 12 & $\begin{array}{l}\text { Escrituras de reconocimientos de } \\
\text { censos, autos, etc. de Valencina }\end{array}$ & 1 & & \\
\hline Idem & Idem de Villanueva del Río & 1 & & \\
\hline Idem & Idem de Utrera & 1 & & \\
\hline
\end{tabular}

Fuente: ADM, «Archivo Ducal. Leg. 14» (Elaboración propia).

Para entonces ya estaba vigente en el Archivo ducal el nuevo ciclo archivístico que nosotros denominamos de la «Desvinculación señorial» ${ }^{79}$, hoy mantenido en el depósito, por otra parte bastante generalizado entre la nobleza española coetánea. Este nuevo ciclo trajo consigo una serie de actuaciones sobre los fondos consistente, por un lado en un cambio en cuanto al sistema de instalación documental, por otro en un reajuste de las secciones del Archivo y, por último, en una modificación los instrumentos de descripción, estableciendo incluso los cauces para la futura archivación (Sánchez, 2014: 104-109).

En cuanto al modo de instalación documental, el cambio consistió en la sustitución de las antiguas papeleras de los depósitos del Archivo General de los Medinaceli por legajos - los mismos que hoy se conservan - que se colocaron en estanterías abiertas, con lo que se modificaba la tradicional reconditez y el carácter arcano que habían caracterizado a los fondos archivísticos durante el Antiguo Régimen por un sistema más abierto y perceptible. Dicho cambio se produjo a fines del siglo XIX y se materializó por el archivero D. Antonio Paz y Mélia, que fuera jefe del Departamento de Manuscritos de la Biblioteca Nacional y miembro del cuerpo de Archiveros, Bibliotecarios y Anticuarios españoles.

79. Se trata del período que arranca con la abolición de los mayorazgos y de los señoríos jurisdiccionales, que coincide con la entrada del régimen político del liberalismo en España, en el que la nobleza sufre una gran transformación que afectó también a sus Archivos (véase Sánchez, 2017). 
Entonces se mantuvo la sección Partido de Sevilla, con 15 legajos como hoy, cuya estructura queda de manifiesto en el cuadro de clasificación del antiguo fondo que aquí recogemos.

TABLA 3. Cuadro de clasificación final del Fondo documental

\section{GESTIÓN DE LA DOCUMENTACIÓN}

1.1. Apuntamientos: informes de los archiveros y decretos del Archivo

2. DESCENDENCIA Y SUCESIÓN

2.1. Fundaciones y agregaciones de mayorazgos

2.2. Posesiones

3. PATRIMONIO

3.1. Cortijo y donadío de Pardales (Utrera)

3.2. Cortijo de Zarracatinejos (Utrera)

3.3. Cortijo de Torralva (Las Cabezas de San Juan)

3.4. Cortijo de la Caja (Villanueva del Camino)

3.5. Cortijos del Toruño y de Miguel de Uceda (Utrera)

3.6. Cortijo y heredad de Montijos (Valencina de la Concepción)

3.7. Cortijos de La Veta, Zancarrona y Caballerías (Las Cabezas de San Juan)

3.8. Casas y terrenos en Triana (Sevilla)

3.9. Tierras y bienes en Sevilla

3.10. Tierras y otros bienes en Villanueva del Camino (Villanueva del Río)

3.11. Huertas y casas en Utrera, Gerena, Alcolea del Río, Constantina y Aznalcóllar

3.12. Otros bienes

4. PATRONATOS Y CAPELLANÍAS

4.1. Capilla de San Pedro de la catedral de Sevilla

4.2. Capellanía de Santillán en la iglesia de Santa Ana de Triana (Sevilla)

5. DOCUMENTACIÓN DE RECUENTO Y CONTROL

5.1. Inventarios de bienes

5.2. Inventarios de escrituras

6. CONTABILIDAD

6.1. Arrendamientos

6.2. Censos

6.3. Juros

7. PLEITOS

7.1. Por la posesión de algunos bienes

7.2. Ejecutorias y concordias

8. VARIOS

8.1. Mercedes, ventas, dispensas, poderes, etc.

Fuente: Elaboración propia.

Ediciones Universidad de Salamanca / @®@@ Stud. his., H. ${ }^{a}$ mod., 43, n. 1 (2021), pp. 229-257 
Así estructurada es como se ha transmitido la documentación del partido o administración de Sevilla de la Casa de Malagón hasta nuestros días.

\section{CONCLUSIONES}

Como hombre de Estado, la huella documental de D. Juan Pardo Tavera ha quedado reflejada en numerosos Archivos españoles (Simancas, Histórico Nacional, Real Chancillería de Valladolid, Nobleza española, General de Andalucía, etc.) y, como figura destacada de la Iglesia española del Quinientos, principalmente además en los Archivos de las diócesis donde ejerció su apostolado (Sevilla, Osma-Soria, Santiago de Compostela y Toledo).

Nosotros solo nos hemos ocupado aquí de la documentación patrimonial que el prelado generó durante su primera etapa sevillana, relativa a unos bienes que justifican en buena proporción la ulterior aparición del Archivo de su familia, los marqueses de Malagón. También, aunque en menor medida, parte de esos mismos bienes, junto con otros muchos que después atesoró Tavera en contraprestación a sus grandes servicios, fueron causantes de la creación de los fondos del hospital toledano de San Juan Bautista, principal legado del cardenal, al que dejó como heredero para servir a los más necesitados.

En definitiva, la adquisición de los bienes patrimoniales que aquí nos han ocupado, por parte de D. Juan Pardo Tavera en el reino de Sevilla durante las primeras décadas del siglo XVI, generó este antiguo fondo documental compuesto por varios centenares de escrituras que hoy se custodian formando parte de esos 15 legajos de la sección Partido de Sevilla del Archivo de la Fundación Casa Ducal de Medinaceli, un fondo que tiene complementariedad no solo en la sección específica de la Casa de Malagón del mismo depósito ${ }^{80}$ sino también, en menor proporción, en determinados documentos sueltos de otras secciones, también de estados de los Medinaceli, con los que tuvieron los Pardo-Tavera relación parental - como las de Santisteban, Castellar y Villalonso-.

Parte de esta documentación ya ha sido dada a conocer, pero solo en aspectos muy parciales ${ }^{81}$, estando pendiente un estudio en profundidad sobre estos bienes adquiridos por el cardenal Tavera en el reino de Sevilla que después sirvieron a

80. Se trata de la sección Malagón del propio ADM, con 30 legajos, archivo familiar de los Pardo-Tavera, al que dedicaremos otro trabajo. Sobre los Malagón, desde 1996 también hay documentos en el Archivo General de Andalucía, dentro del fondo denominado Familia Arias de Saavedra, principalmente en la sección «mayorazgo Tavera», legs. 3755, 3767 y 3772 (véase Torres y Trujillo, 2000: 178-181, 222-223 y 235-239).

81. Por ejemplo, el estudio referido de Franco, 2001. 
la familia Pardo-Tavera para adquirir un estado señorial como el marquesado de Malagón y otros señoríos y propiedades.

De este antiguo fondo patrimonial sevillano, el Archivo de la Casa Ducal de Medinaceli conserva como instrumento de descripción útil aquel antiguo inventario denominado Libro del Partido de Sevilla de alrededor de 1735, refrendo de cuando se organizó inicialmente esta documentación, junto con las fichas catalográficas realizadas por Paz y Mélia a fines del siglo XIX que aún se conservan. El propio sistema orgánico que se estableció en este fondo - como en el resto del Archivocon la documentación descrita, pieza a pieza, en las carpetillas o «guardas» de cada documento por los sucesivos archiveros que llevaron a cabo el trabajo orgánico, ayuda igualmente a la identificación y conocimiento del contenido de toda esta documentación, tan interesante para profundizar principalmente en la etapa sevillana de una figura tan relevante en la historia del Imperio español como fue D. Juan Tavera durante la primera mitad del siglo XVI.

Sirva, además, de contribución al conocimiento de este antiguo fondo la guía que incluimos nosotros aquí en Anexo, con descripción de sus series, las fechas extremas y la signatura de localización de los documentos, como aportación para quien necesite la consulta de esta documentación sevillana que forma parte hoy del Archivo General de la Fundación Casa Ducal de Medinaceli.

\section{BIBLIOGRAFÍA}

Campo Real, F. del. (1997). Malagón: Un señorío en el Campo de Calatrava. Ciudad Real. Campo Real, F. del. (2000). Venta de la encomienda calatrava de Malagón al Mariscal de Castilla don Antonio Ares Pardo de Saavedra. En R. Izquierdo Benito y F. Ruiz Gómez (coords.), Las órdenes militares en la Península Ibérica, 2 (Edad Moderna / por J. López-Salazar Pérez): 1795-1816.

Cardona, M. de (1951). El Cardenal Tavera, colaborador del pensamiento político de Carlos $V$. Madrid: Ministerio de Asuntos Exteriores - Escuela Diplomática.

Castán Lanaspa, J. (1993). A propósito del testamento del cardenal Tavera. Boletín del Seminario de Estudios de Arte y Arqueología, 59, 365-378.

Cepeda Adán, J. (1980). Desamortización de tierras de las órdenes militares en el reinado de Carlos I. Hispania, 146, 487-528.

Cotarelo y Valledor, A. (1902). Fray Diego de Deza: ensayo biográfico. Madrid. Recuperado de http://bibliotecadigital.jcyl.es/es/catalogo_imagenes/grupo.cmd?path=10067267.

Cuartero Huerta, B. y Vargas Zúñiga, A. de (Marqués de Siete Iglesias) (1958-1974). Índice de la Colección de don Luis de Salazar y Castro. 49 vols. Madrid.

Ezquerra Revilla, I. J. (s. a.). Juan Pardo de Tavera. Biografía RAH. Madrid. Recuperado de http://dbe.rah.es/biografias/8545/juan-pardo-de-tavera.

Fernández de Bethencourt, F. (1920). Historia genealógica y heráldica de la Monarquía Española, Casa Real y Grandes de España. Tomo X. Madrid: Tipografía de Jaime Ratés.

Ediciones Universidad de Salamanca / అ@@ Stud. his., H. ${ }^{a}$ mod., 43, n. 1 (2021), pp. 229-257 
Fernández Duro, C. (1891). Colección Bibliográfico-Biográfica de noticias referentes a Zamora y su provincia o Materiales para su Historia. Madrid: Imprenta y Fundición de Manuel Tello.

Franco Silva, A. (2001). La desamortización de bienes de órdenes militares en la época de Carlos V: los casos de Paracuellos y Malagón. En J.L. Castellano y F. Sánchez-Montes (coords.), Carlos V, europeísmo y universalidad: población, economía y sociedad (vol. IV, pp. 237-274). Granada.

Gámez Martín, J. (2014). Inquisición, mitra y carisma. Don Fray Diego de Deza, arzobispo de Sevilla. Brevísima aproximación a un hombre y su época. En F. Lorenzana de la Puente y F. J. Mateos Ascacíbar (coords.), Inquisición. Actas de las XIV Jornadas de Historia en Llerena (pp. 163-176). Llerena: Sociedad Extremeña de Historia.

Gan Giménez, P. (1988). El Consejo Real de Carlos V. Granada: Universidad de Granada. Hanke, L. (ed.). (1978). Los virreyes españoles en América durante el gobierno de la Casa de Austria. Perú. Tomo V. Madrid: Biblioteca de Autores Españoles.

Marías, F. (2007). El Hospital Tavera de Toledo. [Sevilla]: Fundación Casa Ducal de Medinaceli.

Marqués de Lozoya, J. de Contreras y López de Ayala (1967). Historia de España. Tomo IV. Madrid: Salvat.

Martínez-Burgos García, P. (1997). Origen de la teoría artística de la contrarreforma: el cardenal Tavera y el Concilio provincial de Toledo de 1536. En R. Villena Espinosa (coord.), Ensayos humanísticos: homenaje al profesor Luis Lorente (pp. 285-302). Toledo.

Martínez Millán, J. (dir.). (2000). La corte de Carlos V. Segunda parte. Los consejos y los consejeros de Carlos V(III, pp. 316-325). Madrid.

Melgosa Oter, Ó. R. (2017). Los libros del cardenal Tavera: la biblioteca profesional de un hombre al servicio del altar y del trono. Anuario del Instituto de Estudios Zamoranos "Florián de Ocampo» (CSIC), 32, 11-57.

Moxó, S. de (1961). Las Desamortizaciones eclesiásticas del siglo XVI. Anuario de Historia del Derecho Español, 31, 327-361.

Olivera Serrano, C. (1999). La Galicia de Vasco de Aponte: los pleitos del arzobispo Tabera contra los linajes de la Tierra de Santiago. En la España medieval, 22, 285-316.

Otte, E. (2003). Diego Caballero, funcionario de la Casa de la Contratación. En A. Acosta Rodríguez (coord.), La Casa de la Contratación y la Navegación entre España y las Indias (pp. 315-339). Sevilla.

Paz y Remolar, R. (1978). El Cardenal Tavera, asesor político de Carlos V. En Estudios Genealógicos, Heráldicos y Nobiliarios en honor de Vicente de Cadenas y Vicent (pp. 123-127). Madrid: Hidalguía.

Rumeu de Armas, A. (2006). El Cardenal Tavera, Gobernador General de España. Boletín de la Real Academia de la Historia, tomo CCIII, cuaderno II (2006), 163-188.

Salazar y Mendoza, P. de. (1603). Chronico de el Cardenal Don luan Tauera, arzobispo de Toledo. Toledo: Pedro Rodríguez Impresor. http://bdh-rd.bne.es/viewer. vm?id=0000115040\&page $=1$.

Ediciones Universidad de Salamanca / 요 Stud. his., H. ${ }^{a}$ mod., 43, n. 1 (2021), pp. 229-257 
Sánchez González, A. (2014). El Archivo de los Adelantados de Andalucía (Casa de Alcalá). Sevilla: Universidad de Sevilla.

Sánchez González, A. (2015). El Archivo de los Caudillos del reino de Jaén (Casa de Santisteban del Puerto). Jaén: Diputación de Jaén - Instituto de Estudios Giennenses.

Sánchez González, A. (2016a). Heráldica episcopal hispana: la capilla de San Pedro de la Catedral de Sevilla y sus vestigios emblemáticos. Tabularium Edit, 3, 198-224.

Sánchez González, A. (2016b). Dos desconocidos reglamentos de archivos. Vegueta: Anuario de la Facultad de Geografía e Historia, 16, 481-506.

Sánchez González, A. (2017). Nobleza, archivo y mayorazgo. En A. Suárez González (coord.), Escritura y sociedad: la nobleza. Santiago de Compostela: Universidad, 329-342.

Sánchez González, A. (2021a). El Archivo de los mariscales de Castilla, marqueses de Malagón. Espacio, Tiempo y Forma - Serie III: Historia Medieval, 34 (en prensa).

Sánchez González, A. (2021b). El Archivo señorial de Paracuellos, fondo documental de los marqueses de Malagón. Vínculos de Historia, 10 (en prensa).

Sánchez González, A. (2021c). Una fundación familiar del cardenal Tavera: El Hospital de San Juan Bautista en Toledo. Hispania Sacra, vol. 73 (en prensa).

Torres Pegalajar, M. D. y Trujillo Domenech, F. (2000). Fondo de los condes de Gómara y fondo de la familia Arias Saavedra. Catálogo. Sevilla: Junta de Andalucía - Consejería de Cultura.

Zamorano Rodríguez, M. ${ }^{a}$ L. 2002. Historia del Hospital de San Juan Bautista de Toledo durante el siglo XVI (Tesis doctoral). Universidad Complutense de Madrid. http:// eprints.ucm.es/tesis/19911996/D/0/AD0029801.pdf. 
Anexo: Tabla guía general del fondo «Partido de Sevilla», de la Casa de Malagón, en el Archivo Ducal de Medinaceli

\begin{tabular}{|c|c|c|c|c|}
\hline \multirow[b]{2}{*}{ Materias } & \multirow[b]{2}{*}{ Cronología } & \multirow[b]{2}{*}{ SECCIÓN } & \multicolumn{2}{|c|}{ SIGNATURA } \\
\hline & & & $\begin{array}{l}\text { N. }{ }^{\circ} \\
\text { Legajos }\end{array}$ & $\begin{array}{l}\text { N. }{ }^{\circ} \text { Docs. } \\
\text { y Expdtes, }\end{array}$ \\
\hline $\begin{array}{l}\text { - FUNDACIONES DE MAYORAZGOS, } \\
\text { AGREGACIONES Y POSESIONES }\end{array}$ & $1454-1620$ & $\begin{array}{l}\text { PARTIDO } \\
\text { DE } \\
\text { SEVILLA }\end{array}$ & 1 & $1-13$ \\
\hline $\begin{array}{l}\text { Tierras, heredades, cortijos, } \\
\text { Casas y otros bienes } \\
\text { Del Partido de SEVILla: } \\
\end{array}$ & & & & \\
\hline $\begin{array}{l}\text { o Cortijo y donadío de Pardales, } \\
\text { en término de Utrera }\end{array}$ & $1497-1851$ & $”$ & 1 & $14-49$ \\
\hline $\begin{array}{l}\text { o Cortijo de Zarracatinejos, en el } \\
\text { mismo término }\end{array}$ & $1514-1853$ & ” & 1 & $50-60$ \\
\hline $\begin{array}{l}\text { o Cortijo de Torralva, en término } \\
\text { de Las Cabezas de San Juan }\end{array}$ & $1436-1573$ & $”$ & $\begin{array}{l}1 \\
2\end{array}$ & $\begin{array}{c}61-68 \\
1-18\end{array}$ \\
\hline $\begin{array}{l}\text { o Donadío de las Casas, en término } \\
\text { de Villanueva del Camino }\end{array}$ & $1515-1542$ & ” & 2 & $19-24$ \\
\hline $\begin{array}{l}\text { o Cortijos del Toruño y de Miguel } \\
\text { de Uceda, en término de Utrera }\end{array}$ & $1487-1853$ & ” & 2 & $25-50$ \\
\hline $\begin{array}{l}\text { o Cortijo y heredad de Montijos, } \\
\text { en término de Valencina de la } \\
\text { Concepción }\end{array}$ & $1470-1853$ & ” & $\begin{array}{l}2 \\
3\end{array}$ & $\begin{array}{c}51-90 \\
1-37\end{array}$ \\
\hline $\begin{array}{l}\text { o Cortijos de La Veta, Zancarrona } \\
\text { y Caballerías, en término de Las } \\
\text { Cabezas de San Juan }\end{array}$ & $1510-1532$ & ” & 3 & $38-52$ \\
\hline $\begin{array}{l}\text { o Casas y terrenos en Triana } \\
\text { (Sevilla) }\end{array}$ & $1459-1832$ & ” & $\begin{array}{c}3 \\
12\end{array}$ & $\begin{array}{c}53-97 \\
1-4\end{array}$ \\
\hline $\begin{array}{l}\text { o Tierras y bienes en Sevilla y } \\
\text { lugares próximos - algunos hoy } \\
\text { despoblados- de Brihuega, } \\
\text { Sanlúcar la Mayor, Castilleja, La } \\
\text { Barrera, Bollullos del Aljarafe } \\
\text { (o de la Mitación) y otros }\end{array}$ & $1426-1621$ & ” & $\begin{array}{c}4 \\
5 \%\end{array}$ & $\begin{array}{c}1-65 \text { bis } \\
1-35\end{array}$ \\
\hline $\begin{array}{l}\text { o Tierras y otros bienes en Villanueva } \\
\text { del Camino (Villanueva del Río) }\end{array}$ & 1494-1868 & $"$ & $\begin{array}{l}7 \\
8 \\
\end{array}$ & $\begin{array}{c}1-134 \\
1-27 \\
\end{array}$ \\
\hline o Huertas y casas en Utrera & $1472-1577$ & ” & 8 & $28-64$ \\
\hline
\end{tabular}

Ediciones Universidad de Salamanca / అ@@ Stud. his., H. ${ }^{a}$ mod., 43, n. 1 (2021), pp. 229-257 


\begin{tabular}{|c|c|c|c|c|}
\hline \multirow[b]{2}{*}{ Materias } & \multirow[b]{2}{*}{ Cronología } & \multirow[b]{2}{*}{ SECCIÓN } & \multicolumn{2}{|c|}{ SIGNATURA } \\
\hline & & & $\begin{array}{l}\text { N. }{ }^{\circ} \\
\text { Legajos }\end{array}$ & $\begin{array}{l}\text { N. Docs. } \\
\text { y Expdtes, }\end{array}$ \\
\hline o Huertas y casas en Gerena & $1524-1623$ & $\begin{array}{l}\text { PARTIDO } \\
\text { DE } \\
\text { SEVILLA }\end{array}$ & 8 & $65-76$ \\
\hline $\begin{array}{l}\text { o Huertas y casas en Alcolea del } \\
\text { Río, Constantina y Aznalcóllar }\end{array}$ & $1483-1570$ & " & $\begin{array}{l}8 \\
9 \\
\end{array}$ & $\begin{array}{c}77-91 \\
1-23 \\
\end{array}$ \\
\hline $\begin{array}{l}\text { o Rentas en El Puerto de Santa } \\
\text { María (Cádiz) }\end{array}$ & $(1458-1572)$ & - & - & - \\
\hline $\begin{array}{l}\text { o Bienes en ellugarde Gelo, alquería } \\
\text { en el término de Aznalcázar } \\
\text { - hoy de Benacazón-(Sevilla) }\end{array}$ & $1446-1499$ & ” & 10 & $1-7$ \\
\hline $\begin{array}{l}\text { o Bienes en el lugar de Villoruela } \\
\text { (Salamanca) }\end{array}$ & 1700 & ” & 10 & 8 \\
\hline- JuROS & $1508-1561$ & ” & 9 & $24-56$ \\
\hline- Censos & $1532-1715$ & $”$ & 15 & $1-13$ \\
\hline - PATRonatos y CAPELlaníAs: & & & & \\
\hline $\begin{array}{l}\text { o Capilla de San Pedro, en la } \\
\text { catedral de Sevilla }\end{array}$ & $1525-1578$ & ” & 9 & $57-68$ \\
\hline $\begin{array}{l}\text { o Capellanía en la iglesia de Santa } \\
\text { Ana de Triana (fundaciones de } \\
\text { Gómez de Santillán e Isabel de } \\
\text { Saavedra, hija del mariscal de } \\
\text { Castilla Gonzalo de Saavedra) }\end{array}$ & $1498-1769$ & ” & 9 & $69-97$ \\
\hline $\begin{array}{l}\text { - VArios: Pleitos, mercedes, ventas, } \\
\text { dispensas, arrendamientos, } \\
\text { inventarios de bienes, ejecutorias, } \\
\text { concordias, poderes, etc. }\end{array}$ & $1454-1707$ & $\begin{array}{l}" \\
" \\
" \\
" \\
"\end{array}$ & $\begin{array}{c}6 \\
10 \\
11 \\
12 \\
13 \\
14 \\
\end{array}$ & $\begin{array}{c}1 \\
9-54 \\
1-32 \\
1-2 \\
1-2 \\
1-2 \\
\end{array}$ \\
\hline - Apuntamientos: & & & & \\
\hline $\begin{array}{l}\text { o Informes elaborados por los } \\
\text { archiveros sobre diversas } \\
\text { materias relacionadas con los } \\
\text { bienes de la Casa de Malagón en } \\
\text { el partido de Sevilla }\end{array}$ & Siglo XIX & ” & 15 & 14 \\
\hline
\end{tabular}

* Esta documentación salió del Archivo.

Ediciones Universidad de Salamanca / @®@@ Stud. his., H. ${ }^{a}$ mod., 43, n. 1 (2021), pp. 229-257 